based. ${ }^{4}$ Specifically, Lombardy's healthcare service is considered a benchmark in terms of quality and efficiency. ${ }^{5}$

In Lombardy, region of $\sim 10$ million people, the pre-crisis total intensive care unit (ICU) bed capacity was of $\sim 720$ beds, with a mean occupancy rate in the winter months of $85 \%-90 \%{ }^{2}$ To deal with SARS-CoV-2 outbreak, the number of ICU beds has significantly increased, and several departments have been reorganized and dedicated exclusively to COVID-19 patients. Nonetheless, hospitals in Lombardy are dramatically overcrowded with lack of medications, mechanical ventilators, oxygen, and personal protective equipment (PPE). ${ }^{6}$ Clearly, the increased number of cases is posing a serious threat to the entire SSN. ${ }^{7}$

We believe that the following numbers regarding the Lombardy region help to fully measure and elucidate the medical and social impact of SARS-CoV-2 outbreak.

The Italian National Institute of Health (ISS) reported that 4,451 people died in Lombardy due to SARS-CoV-2 complications between January 3 and March 25, 2020. ${ }^{3}$ In March 2019, there were 9,062 deaths, with 292 deaths per day ${ }^{8}$; in March 2020, the number of deaths per day was exceeded for 8 days by the number of deaths of confirmed COVID-19 patients alone. The most deadly day was March 21, with 546 daily fatalities due to COVID-19.

To date, 11,262 COVID-19 patients have been hospitalized1,236 in an ICU. More than 5,000 healthcare workers have been infected across Italy, accounting for $9 \%$ of total cases. This number particularly reflects the lack of PPE and the unexpected pressure on the SSN. ${ }^{3}$

This report highlights how the impact and the consequences of the COVID-19 pandemic have been largely underestimated in Western countries, and it raises concerns about the potential responsiveness of healthcare systems in less-developed countries.

\section{Acknowledgments.}

Financial support. No financial support was provided relevant to this article.

Conflicts of interest. All authors report no conflicts of interest relevant to this article.

\section{References}

1. WHO virtual press conference on COVID-19-11 March 2020. World Health Organization website. https://www.who.int/docs/default-source/coronaviruse/ transcripts/who-audio-emergencies-coronavirus-press-conference-full-and-final11mar2020.pdf?sfvrsn=cb432bb3_2. Published 2020. Accessed March 23, 2020.

2. Onder G, Rezza G, Brusaferro S. Case-fatality rate and characteristics of patients dying in relation to COVID-19 in Italy. JAMA 2020 [Epub ahead of print]. doi: 10.1001/jama.2020.4683

3. COVID-19 Surveillance Group-Istituto Superiore di Sanità. Epicentro website. https://www.epicentro.iss.it/coronavirus/sars-cov-2-sorveglianza-dati. Published 2020. Accessed March 25, 2020.

4. Christopher JL, Murray JA, Lauer DB, et al. Measuring overall health system performance for 191 countries. World Health Organization website. https://www.who.int/healthinfo/paper30.pdf. Published 2011. Accessed March 24, 2020.

5. Bosio M, Meroni P. Quality and efficiency of the health service in the Italian region of Lombardy. G Ital Nefrol 2002;19(Spec No. 21):S28-S32.

6. Nacoti M, Ciocca A, Giupponi A, et al. At the epicenter of the COVID-19 pandemic and humanitarian crises in Italy: changing perspectives on preparation and mitigation. NEJM Cathalyst Innov Care Deliv 2020;1(2) [Epub ahead of print]. doi: 10.1056/CAT.20.0080.

7. Saglietto A, D'Ascenzo F, Zoccai GB, et al. COVID-19 in Europe: the Italian lesson. Lancet 2020 [Epub ahead of print]. doi: 10.1016/S0140-6736 (20)30690-5.

8. Istituto nazionale di statistica (ISTAT), Statistiche demografiche website. http://demo.istat.it/bilmens2019gen/index.html. Published 2019. Accessed March 24, 2020.

\title{
The largest epicenter of the coronavirus outbreak in Vietnam
}

\author{
Trang H.D. Nguyen ${ }^{1,2}$ and Danh C. $\mathrm{Vu}^{3}$ (1) \\ ${ }^{1}$ Institute of Biotechnology and Food Technology, Industrial University of Ho Chi Minh City, Vietnam, ${ }^{2}$ Food for Health Center, University of Nebraska, Lincoln, \\ Nebraska, United States and ${ }^{3}$ Faculty of Technology, Van Lang University, Ho Chi Minh City, Vietnam
}

To the Editor-As of April 1, the total number of SARS-Cov2-positive cases in Vietnam reached 218, and 37 of these were infected within a public hospital in Hanoi, the capital of Vietnam. ${ }^{1}$ Thus far, this hospital is the largest COVID-19 hotspot in the country.

Three patterns of transmission occurred in the hospital: (1) between healthcare workers (HCWs), (2) from COVID-19 patients to HCWs, and (3) from nonclinical hospital staff to others. Figure 1 illustrates a timeline of the spread of the SARS-Cov-2 virus within the hospital from the first confirmed case on March 20 to the most

\footnotetext{
Author for correspondence: Danh C. Vu, E-mail: dcvgwc@mail.missouri.edu Cite this article: Nguyen THD and Vu DC. (2020). The largest epicenter of the coronavirus outbreak in Vietnam. Infection Control \& Hospital Epidemiology, 41: 984-985, https://doi.org/10.1017/ice.2020.128
}

recent case on April 1. The first SARS-Cov-2-positive case was a medical worker (P87), who was in close contact with a SARSCov-2-infected nurse (P86). ${ }^{2}$ With the exception of the 2 infected cases, P86 and P28, who contracted the coronavirus from the outside, no HCW, non-COVID-19 inpatients, or visitors had tested positive for the coronavirus. Since March 28, SARS-CoV-2 infections among nonclinical staff have emerged, and subsequently, 25 of the 37 COVID-19 cases (68\%) were nonclinical staff working in the dining hall of the hospital. These catering workers were responsible for preparing meals and delivering food and hot water to patients and visitors across the hospital daily, and it is likely that these nonclinical staff are the main contributors to the spread of the virus within the hospital. Healthcare-associated infection is known characteristic of coronavirus-related diseases and a leading route of transmission. ${ }^{3}$ 


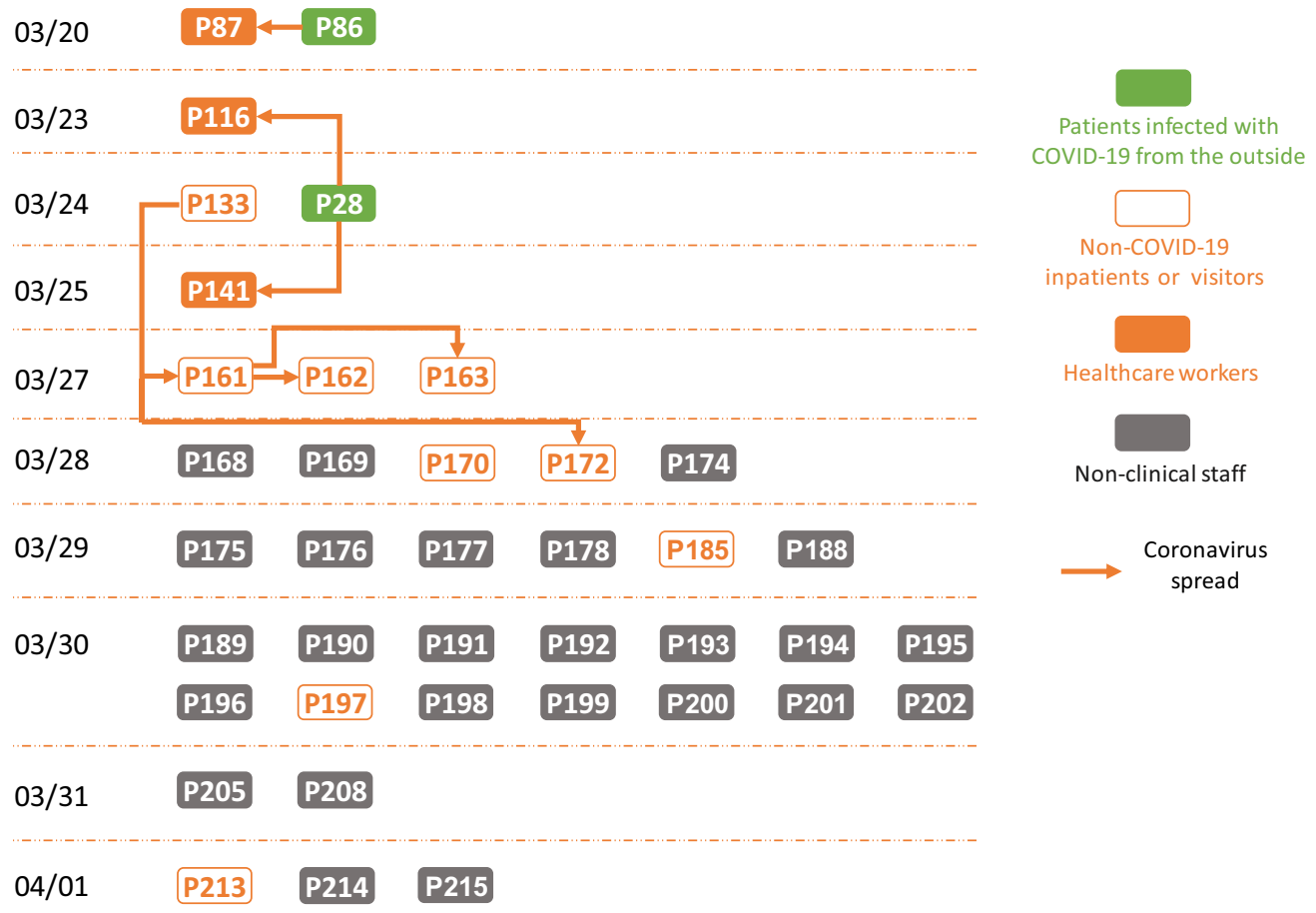

Fig. 1. The chronology of the confirmed cases of COVID-19 in the public hospital where the first healthcare associated COVID-19 infections occurred (as of April 1, 2020). Each rectangle represents a patient numbered by the Vietnam Ministry of Health.

Because the confirmed cases linked to healthcare-acquired infection have only very recently been revealed and are increasing in Vietnam, several measures have been implemented to stop the spread of the disease in this hospital ${ }^{4}$ :

1. The admission of new patients has been suspended in this hospital. Approximately 5,000 employees and non-COVID-19 inpatients of the hospital are being tested for coronavirus. Current patients are discharged only allowed if they test negative.

2. Quick COVID-19 tests have been conducted for those having close contacts with the nonclinical staff and residents living nearby the hospital.

3. Immediate lockdown has been imposed on the hospital units involved in the COVID-19 spread, and as of March 28, on the entire facility. Disinfection was conducted at the hospital in the evening of the same day.

Based on the transmission dynamics described earlier, we conclude that the major contributing factor to the significant increase in healthcare-acquired infections is extensive access of nonclinical staff across the hospital. These nonclinical workers did not properly implement effective personal protection and lacked sufficient preparedness for the emerging infectious disease during their work shifts, leading to cross contamination between the hospital units.

After the implementation of lockdown at the hospital and other mitigation measures, the numbers of new confirmed cases reported on March 31 and April 1 have begun to decrease. However, this decrease does not indicate that the outbreak in the hospital has been successfully eliminated. Therefore, in addition to the measures above, the hospital should take into consideration the following suggestions to stave off widespread coronavirus transmission in this healthcare facility and in the community:

1. Makeshift healthcare facilities are needed to accommodate non-COVID-19 outpatients and visitors as well as HCWs.
2. Because evidence increasingly favors the use of face masks, nonclinical staff should strictly wear new face masks and gloves and should update their daily health status using COVID-19 monitoring apps, such as NCOVI software developed for Vietnamese citizens.

3. Transparency in healthcare leaders' response to the COVID19 infections should be prioritized for the COVID-19 illness.

4. A targeted educational strategy to improve COVID-19 health literacy and knowledge for nonclinical staff in hospitals should be urgently considered.

We offer our experience with the COVID-19 outbreak and subsequent recommendations to benefit other hospitals and institutions similarly fighting this disease worldwide.

Acknowledgments. None.

Financial support. No financial support was provided relevant to this article.

Conflicts of interest. All authors report no conflicts of interest relevant to this article.

\section{References}

1. Bộ Y tế. Trang tin về dịch bệnh viêm đường hô hấp cấp Covid-19. Vietnamese Ministry of Health website. https://ncov.moh.gov.vn/. Published 2020. Accessed on April 1, 2020.

2. Tuổi trẻ News. https://tuoitrenews.vn/news/society/20200320/nurses-catchnovel-coronavirus-in-vietnam/53589.html. Published 2020. Accessed on March 20, 2020.

3. Al-Tawfiq JA, Auwaerter PG. Healthcare-associated infections: the hallmark of Middle East respiratory syndrome coronavirus with review of the literature. J Hosp Infect 2019;101:20-29.

4. VNExpress Internationals website. https://e.vnexpress.net/news/news/ hanoi-locks-down-main-hospital-after-eight-covid-19-infections-4076150. html. Published 2020. Accessed on March 28, 2020. 